Revista Destaques Acadêmicos, Lajeado, v. 12, n. 1, 2020. ISSN 2176-3070

DOI: http://dx.doi.org/10.22410/issn.2176-3070.v12i1a2020.2510 http://www.univates.br/revistas

\title{
GESTÃO EMOCIONAL: O DESENVOLVIMENTO E A IMPORTÂNCIA DA EMOÇÃO PARA AS ORGANIZAÇÕES
}

\author{
Anderson Luis do Espirito Santo ${ }^{1}$, João Henrique Miranda de Sousa ${ }^{2}$
}

Resumo: A busca pela eficiência dentro das organizações tem sido uma das bases da existência da Administração desde a sua origem. Outrora aspirava-se melhorar a eficiência através do planejamento físico e do treinamento técnico. Hoje a gestão da emoção faz parte do cotidiano das organizações. Este artigo objetiva apresentar a importância da gestão emocional para o desempenho das organizações e a sua importância para o avanço da ciência da Administração. Para isso realizou-se um aprofundamento teórico e uma coleta de dados na base SPELL. Os resultados mostram que a produção atual é baixa e as primeiras teorias administrativas visavam controlar as emoções e os sentimentos. No entanto, hoje é crescente a necessidade de se avaliar o impacto do bem-estar emocional no desempenho profissional e na busca pela eficiência da organização, logo estudá-las é decisivo para o entendimento.

Palavras-chave: Teoria das Organizações, Emoção, Gestão Emocional, Emoção nas Organizações, Administração.

\section{INTRODUÇÃO}

Este artigo tem como objetivo compreender como a emoção foi percebida pelas principais teorias administrativas e como ela vem sendo empregada nos estudos e pesquisas da Administração no Brasil. Mais especificamente

1 Doutorando em Administração na Universidade do Estado de Santa Catarina (UDESC) e pesquisador do Núcleo de Inovações Sociais na Esfera Pública (NISP). Mestre em Estudos Fronteiriços pela Universidade Federal de Mato Grosso do Sul (UFMS). Bacharel em Administração pela UFMS. Professor do curso de Administração na UFMS, Campus do Pantanal. Tem experiência e interesse de pesquisa nos seguintes temas: Epistemologia da Ciência da Administração. Sociologia Pragmática. Sociedade Civil, Inovação Social e Desenvolvimento Territorial Sustentável. Estudos Fronteiriços.

2 Bacharel em Administração pela Universidade Federal de Mato Grosso do Sul, Campus do Pantanal. Especialista em Gestão de Pessoas (Universidade Católica Dom Bosco). Técnico Administrativo na UFMS. Tem interesse nas seguintes áreas: Estudos Organizacionais; Sociologia das Emoções; Psicologia Organizacional; Métodos de Pesquisa. 
buscamos apresentar a importância da gestão emocional para o desempenho das organizações e a sua importância para o avanço da ciência da Administração.

A Administração é a ciência que surge das práticas e a busca pela eficiência dentro das organizações tem sido uma das bases da sua existência desde os áureos tempos de Taylor e Fayol, quando se objetivava o ganho de agilidade advindo das primeiras linhas de montagem através da especialização da mão de obra. Porém, as dinâmicas de desenvolvimento dos últimos 30 anos indicam que hoje a Administração deve buscar, além da eficiência, da melhor organização física e do treinamento técnico, a valorização dos indivíduos e uma maior participação com a sociedade civil (CHANLAT, 2008).

Desde a década de 1970-80 as pesquisas da Administração vêm se reinventando e se redescobrindo colocando em xeque antigos paradigmas que fomentaram a popularização dos clássicos manuais da Teoria Geral da Administração (TGA) visto que o seu quadro teórico passou a limitar uma melhor e maior compreensão sobre os aspectos do fator humano dentro das organizações. Sob uma perspectiva kuhniana podemos compreender que o referencial teórico destes manuais que era visto como suficiente, sólido e normal, passou a ser questionado - e a crise sobre o ensino e a formação dos administradores desmantelou-se em diversas áreas e escolas de Administração ${ }^{3}$.

Para o professor Jean-François Chanlat (1990; 2008) foi a partir desse período que se iniciou um movimento intenso dentro da Administração que se propôs a reformular diversos estudos sobre o comportamento humano, a partir do momento em que dimensões normalmente esquecidas do mundo dos negócios passaram a fazer parte da agenda dos pesquisadores, tais como a cultura, o sofrimento no trabalho, o bem estar e a participação na sociedade, as relações interculturais dentre outros temas. No entanto, o autor aponta que estas reformulações só foram possíveis quando os pesquisadores começaram a retomar diversos campos do conhecimento, até então, considerados marginais à Administração, como a Psicologia do Trabalho, a Sociologia, a Antropologia, a Filosofia e outros. A partir dessa retomada interdisciplinar, diferentes estudos tendo o indivíduo como objeto principal, começaram a emergir como liderança, comunicação, dinâmica de grupo, stress e conflitos. Com o desenvolvimento de novas pesquisas e com o avanço da sociedade uma nova visão foi emergindo neste espaço, dando início aos estudos sobre a emoção no processo de organizar.

3 Apesar do desenvolvimento de novos estudos na Administração decorrente de diversas influências epistemológicas e paradigmáticas, fundamentada em inúmeras teorias e múltiplas análises do campo, reconhecemos que é notório a influência que os manuais da TGA ainda exercem sobre o ensino, a pesquisa e a formação dos administradores. Em um estudo recente Cruz e Ross (2018) elencam uma série de deslizes pelos quais o pesquisador pode incorrer. Uma delas é "o uso de manuais na fundamentação teórica", onde os autores não negligenciam a importância dos manuais para a construção do conhecimento, contudo, defendem que esta prática pedagógica acaba por limitar múltiplos olhares dos administradores. 
Os estudos que tem por objeto a compreensão dos sentimentos e do estado emocional dos trabalhadores começaram a surgir com maior frequência nos Estados Unidos, a partir de trabalhos clássicos a destacar os de Arlie Hochschild ${ }^{4}$, Theresa Domagalski, Stephen Fineman, Blake Ashforth e Ronald Humphrey, para citar alguns. Das contribuições francófonas destacamos o vasto trabalho de Jean-François Chanlat que não se dedicou a estudar unicamente a emoção nas organizações, mas a olhar para os indivíduos a partir de uma influência antropológica.

A realidade do mundo atual é marcada por intensas transitoriedades, neste caso, representadas por indivíduos que buscam no trabalho muito além do que apenas seu sustento, ou a estabilidade na carreira. Mais do que isso, estes indivíduos procuram por organizações que olhem para si e para a sua equipe não como força de trabalho, um objeto solucionador de problemas, ou uma fonte de ideias. Hoje, eles buscam organizações que percebam sua singularidade, personalidade e seus sentimentos. Preferem organizações que interajam e tenham incidência no desenvolvimento da sociedade onde está inserida e que estimulem sua capacidade de trabalho através de desafios. Para Chanlat $(1990 ; 2008)$ quando estas necessidades não são materializadas surgem os efeitos negativos para as organizações, como doenças do trabalho, rotatividade de pessoal, pedidos de demissões e outras. Já para os indivíduos pode ocorrer a baixa auto-estima, a tristeza e o sofrimento no trabalho.

Apesar do (re)conhecimento deste cenário a maioria das organizações não se preocupa com os sentimentos nem com o estado emocional da sua equipe. Nesse sentido, autores como Hochschild (1979; 1983), Fineman (2001) e Ashforth e Humphrey (1995) apresentam que as empresas criam regras sobre o comportamento dos seus colaboradores - impondo às pessoas que demonstrem emoções benéficas a imagem da empresa e ao relacionamento interpessoal, gerando um conflito interno entre como o colaborador se sente e como ele deveria se comportar. Segundo esses autores, existem evidências de que o estado emocional dos indivíduos afeta o seu raciocínio e, dessa forma, o seu desempenho geral nas mais variadas tarefas. Fineman (2001) indica que os estudos sobre esse impacto é escasso e por vezes, limitado a formas superficiais de estudar as emoções, como o estresse, a satisfação, a motivação, o clima e a liderança ${ }^{5}$.

Este artigo estrutura-se em cinco partes. Inicia-se pela introdução e estratégia de pesquisa e segue para o referencial teórico que apresenta à

4 As principais obras destes autores estão citadas nas referências deste artigo

5 No Brasil essa superficialidade se dá, principalmente em razão da utilização dos clássicos manuais citados inicialmente. Todavia, há estudos que fogem dessa depreciação e aborda a temática da emoção em profundidade, como os realizados pelas pesquisadoras Mirele Bonfim e Sônia Gondim (2010). 
temática. Durante todo o texto são apresentados quadros que compilam como a gestão emocional pode ser estudada na Administração. Posteriormente são apresentados os resultados, iniciando com a trajetória da emoção desde as primeiras teorias administrativas até a sua grande propagação na década de 1970-80. Depois apresentando como as emoções são percebidas pelas publicações brasileiras, findando com as considerações finais e subsequente referências.

\section{PROCEDIMENTOS METODOLÓGICOS}

A discussão dessa pesquisa centra-se na importância de desenhar a gestão emocional para as organizações e, logicamente, o desenvolvimento científico da Administração. Para tanto, este estudo foi construído de forma teórico-analítica, a partir de uma abordagem qualitativa, fundamentada em revisão teórica seletiva sobre a literatura que versa sobre o tema e uma coleta de dados na base SPELL (Scientific Periodicals Electronic Library).

Ao defendermos que a Administração é uma ciência que surge das práticas temos que o seu desenvolvimento científico sempre esteve concatenado aos questionamentos da sociedade, o que estimula o surgimento de novas pesquisas. Assim, a abordagem qualitativa foi à escolhida por possibilitar ao pesquisador a capacidade de ver o mundo social através do seu ponto de vista (SANTO, 2018). Aqui a pesquisa qualitativa caracteriza-se pela descrição, compreensão e interpretação dos fatos e fenômenos identificados a partir das teorias sobre a gestão da emoção.

A pesquisa bibliográfica foi feita de forma intensa a partir dos clássicos que abordam a temática da emoção no processo organizacional. Optou-se por estruturar o resultado dessa etapa em forma de ensaio teórico, a partir de uma proposta teórico-analítica, com o intuito de que sejam elaboradas pesquisas futuras sobre esta vertente de se ver e interpretar a emoção.

Por fim, para identificar como a emoção está sendo empregada nas pesquisas da Administração no Brasil foi realizada uma busca no indexador SPELL. Esta base foi escolhida por condensar a produção da área da Administração Pública e de Empresas, Contabilidade e Turismo. Foi realizada uma busca com o termo "emoção" e obteve-se 14 resultados. Após a leitura dos artigos foram criadas 04 categorias analíticas a partir da visão/foco da emoção que cada artigo apresenta. Isso ajudou na redação deste texto, pois os artigos foram agrupados conforme a categoria criada. Cabe salientar que tanto o fichamento da pesquisa bibliográfica, quanto à organização e a leitura dos artigos encontrados na SPELL foram organizados no software Microsoft Excel 2016, que permitiu um melhor tratamento dos dados e possibilitou a criação de todos os quadros apresentados neste estudo. 


\section{REFERENCIAL TEÓRICO}

\subsection{A EMOÇÃO NAS ORGANIZAÇÕES}

Ao analisar as teorias organizacionais é possível perceber que os pesquisadores têm demorado a considerar as emoções e os sentimentos nos estudos sobre o comportamento nas organizações. Esse cenário começou a mudar nas últimas décadas, devido às influências da psicologia (comportamental e clínica) e principalmente os estudos na área da sociologia. Para Fineman (2001) o estado emocional está presente e afeta o desenvolvimento do trabalho, positivamente ou negativamente, em atividades que envolvam "tomar decisões, negociar, aconselhar, vender, participar de reuniões, empregar/demitir pessoas, são mais que um conjunto de respostas automáticas. São sentidas e formadas por sentimentos" (Op.cit, p.157).

Ashforth e Humphrey (1995, p.97) afirmam que "as emoções são uma parte integral e inseparável do dia a dia da vida organizacional. De momentos de frustração ou alegria, dor ou medo, a experiência do trabalho está saturada de sentimentos". Entretanto, mesmo estando presentes nas organizações, as emoções geralmente são vistas de forma negativa no cotidiano das empresas, levando a criação de mecanismos com o objetivo de regular como e quais emoções serão expressas e a forma como serão vividas. Essa visão negativa da emoção se deve principalmente à crença de que a emoção é o oposto da racionalidade.

Cruzando os estudos de Hochschild (1979; 1983), Salovey e Mayer (1990) e Ashkanasy (2002), temos que no desempenho de suas funções as pessoas devem demonstrar emoções pré-determinadas pela organização e, essas emoções, nem sempre correspondem ao que a pessoa realmente sente. Além de tentar manipular quais emoções serão expressas, o indivíduo pode tentar mudar o que sente para corresponder ao que é exigido pela organização, sacrificando as próprias emoções, como pagamento pela aceitação no ambiente de trabalho. Porém, é preciso abandonar a visão de que o trabalho é puramente racional e entender que o trabalho de cada empregado afeta o emocional de cada um, o que impactará nas atividades da organização que não são locais frios onde as pessoas apenas executam ordens.

Ao longo deste trabalho, emoção e sentimento serão tratados como sinônimos, pois os dois termos estão inter-relacionados (ASHKANASY, 2002), possuem o mesmo valor e recebem o mesmo tratamento no contexto organizacional. O quadro 1 apresenta um levantamento conceitual de emoção e, por vezes, de sentimento (quando tratado pelo autor). 


\begin{tabular}{|c|c|}
\hline AUTORES & DEFINIÇÃO \\
\hline $\begin{array}{c}\text { Salovey } \\
\text { e Mayer, } \\
\text { 1990, p.186 }\end{array}$ & $\begin{array}{l}\text { Emoções como respostas organizadas, cruzando as fronteiras de } \\
\text { muitos subsistemas da psicologia, incluindo o fisiológico, cognitivo, } \\
\text { motivacional e sistemas experienciais. Emoções tipicamente surgem } \\
\text { em resposta a um evento, tanto interno quanto externo, que tem um } \\
\text { significado válido positivamente ou negativamente para o indivíduo. } \\
\text { Emoções podem ser distinguidas do conceito intimamente ligado de } \\
\text { humor na medida em que emoções têm duração mais curta e geralmente } \\
\text { mais intensa. }\end{array}$ \\
\hline $\begin{array}{l}\text { Fineman, } \\
\text { 2001, p.162 }\end{array}$ & $\begin{array}{l}\text { Sentimento é essencialmente a experiência subjetiva - que está no } \\
\text { âmago da maioria das definições de emoção. Sentir significa que } \\
\text { estamos cientes, no interior de nós mesmos, de algum estado corporal, } \\
\text { perturbação ou mudança psicológica mais difusa. Alguns sentimentos } \\
\text { podem ser em parte determinados por experiências e expectativas da } \\
\text { infância - fontes das quais podemos não ter consciência. }\end{array}$ \\
\hline $\begin{array}{l}\text { Ashforth e } \\
\text { Humphrey, } \\
\text { 1995, p.23. }\end{array}$ & $\begin{array}{l}\text { Emoções podem ser definidas, em termos muito abrangentes e } \\
\text { inclusivos, englobando emoções básicas (como alegria, amor e raiva) } \\
\text { e emoções sociais (como vergonha, culpa e inveja), incluindo também } \\
\text { construções como afeto, humor e sentimento. Esses estados emocionais } \\
\text { podem variar muito em termos de duração, intensidade, consistência e } \\
\text { quanto à forma como são percebidos pelos demais. }\end{array}$ \\
\hline $\begin{array}{c}\text { Domagalski, } \\
\text { 1999, p.34. }\end{array}$ & $\begin{array}{l}\text { Emoção é descrita tanto como um evento fisiológico, interno e } \\
\text { individual, em resposta a um estímulo; quanto como um fenômeno } \\
\text { de construção social. Esse último significado é o mais importante para } \\
\text { a administração, pois considera a natureza social das emoções, e não } \\
\text { exclusivamente como eventos isolados e individuais. }\end{array}$ \\
\hline
\end{tabular}

Fonte: Os autores fundamentados nos autores descritos na primeira coluna.

Este artigo interpretará a emoção, inspirado em Bonfim e Gondim (2010) que estudam a emoção há muito tempo no Brasil. Dessa forma, emoção são alterações fisiológicas e corporais que surgem devido à ação-estímulos, imediata, que pode ser interna ou externa e que, de alguma forma, parece não estar sob o consciente do indivíduo. Sentimento é uma experiência provada, intrínseca, resultante de sensações e pensamentos. A emoção seria a manifestação dos sentimentos que pode ser observada pelos demais membros do grupo. Já o afeto é tudo aquilo que te afeta. "Seria uma categoria mais ampla, abarcando as emoções, os sentimentos, os humores e os temperamentos" (Op.cit, p.20).

Compreende-se dessa forma que a emoção (como medo, tristeza, alegria, amor e raiva) é vista como resultado automático de um evento no ambiente individual ou social, com importância para o indivíduo, podendo englobar uma ampla gama de significados e incluindo termos relacionados que se tornam sinônimos em determinadas situações. Enquanto o sentimento (como irritação, tédio, receio e excitação) é baseado na ponderação das experiências e expectativas sobre o evento, sendo mais profundo e podendo incluir elementos desconhecidos pelo indivíduo. 


\subsection{A EMOÇÃO ENQUANTO OBJETO DE PESQUISA}

Fineman (2001) e Brook (2009) afirmam que a emoção começa a se tornar objeto de estudo na década 1990 e isso se deve as pesquisas nos campos da psicologia e sociologia sobre as emoções e, anterior a essa época, ela não era considerada. O local de trabalho passou a ser visto pelo aspecto emocional, principalmente após a publicação do livro "The managed heart: commercialization of human felling 6" $^{\prime \prime}$ (1983) de autoria da socióloga e professora americana Arlie Hochschild, uma das pioneiras da chamada sociologia emocional, sendo o seu trabalho conhecido por criticar o custo emocional para manutenção do sistema econômico e o dano psicológico em decorrência de um alto grau de esforço emocional.

Domagalski (1999) apresenta que estudar a emoção é fundamental para o entendimento do funcionamento das organizações e esse pensamento teve forte influência nas pesquisas de Fineman, Ashforth e Humphrey, entre outros pesquisadores. Stephen Fineman, pesquisador do comportamento organizacional e professor cujo foco são as emoções nas organizações, publicou em 1993 o livro "Emotion in Organizations", , onde aborda a falta de valor dado a emoção dentro da organização ao longo do tempo; o dualismo entre emoção e racionalidade; as influências das emoções nas tarefas; e o controle exercido pela organização sobre as emoções dos indivíduos. Ao perscrutar as análises de Fineman (2001), compreende-se que o britânico foi capaz de reunir conhecimentos de inúmeras áreas - como psicologia, psicanálise, ciências políticas, economia, sistemas informacionais, medicina do trabalho e sociologia, para então, correlacioná-los com a Administração a partir de estudos da estrutura organizacional e, principalmente, aos estudos do comportamento organizacional. Desde então, Fineman vem publicando seus estudos onde complementa, atualiza e propõe novos conhecimentos a partir do que defendeu em 1993.

Outra contribuição notável vem da parceria entre Blake Ashforth, professor e pesquisador da estrutura organizacional e processos e Ronald Humphrey que pesquisa como a estrutura organizacional e o trabalho influencia os processos cognitivos e emocionais. Blake e Ronald publicaram em 1995 o artigo "Emotion in the workplace: a reappraisal"," onde abordam a falta de valor dado a emoção como resultado da visão pejorativa de que a emoção e a racionalidade são opostas; surgem a partir de normas e mecanismos para

6 Tradução nossa: “O coração gerenciado: comercialização do sentimento humano".

7 "A emoção e o processo de Organizar" - tradução do Handbook de Estudos Organizacionais, vol.2.

8 Tradução nossa: Emoção no local de trabalho: uma reavaliação. 
regulá-las e como elas estão presentes e afetam a motivação, a liderança e as dinâmicas de grupo.

\subsection{A IMPORTÂNCIA DAS EMOÇÕES PARA AS ORGANIZAÇÕES.}

Rafaeli e Worline (2001) defendem que o indivíduo está predisposto a imaginar as emoções como algo próprio, como a parte mais íntima de si mesmo, porém as emoções estão conectadas a outras pessoas e ao ambiente, onde está inserido o indivíduo. Em decorrência dessa conexão ao ambiente, ao tempo despendido e a importância para a manutenção do indivíduo, o local de trabalho é o espaço onde as emoções mais serão exteriorizadas. Segundo as autoras, é no trabalho que o indivíduo encontra pessoas, prepara relatórios, participa de reuniões ou trabalha com o computador. Executar todas essas tarefas exige treino e habilidade, mas também gerir as emoções. Se sentir entediado, excitado, frustrado, feliz ou com raiva são exemplos das formas como o indivíduo pode notar o trabalho.

Para Domagalski (1999) as pesquisas na Administração têm ignorado a existência das emoções nas organizações e a maioria dos trabalhos foca apenas as emoções negativas. Frequentemente as emoções são vistas pejorativamente como o oposto da racionalidade, sendo indesejáveis para o ambiente de trabalho ideal. A organização só alcançaria a eficiência ao eliminar e controlar as emoções e sua expressão e controlar a racionalidade.

Inspirado em Ashforth e Humphrey (1995), Fineman (2001) e Rafaeli e Worline (2001), temos que a visão exageradamente racional das organizações e nos consequentes esforços para controlar as emoções, tem dificultado o reconhecimento da utilidade das emoções dentro do ambiente organizacional. Segundo os autores, a emoção poderia contribuir para o melhoramento de tradicionais conceitos organizacionais que, historicamente, são limitados pelos manuais de Administração, como os apresentados no quadro 2. 
Quadro 2 - A nova visão da emoção dentro do ambiente organizacional

\begin{tabular}{|c|c|}
\hline CONCEITO & NOVA VISÃO \\
\hline Motivação & $\begin{array}{l}\text { Os estudos sobre motivação revelam uma visão exageradamente } \\
\text { racional. Basicamente é dito que o indivíduo é motivado a mudar } \\
\text { seu comportamento para atingir os resultados esperados, ou seja, } \\
\text { as recompensas. "A imagem é de uma troca racional: o empregado } \\
\text { essencialmente barganha esforços por pagamento, segurança, } \\
\text { promoções, e assim por diante" (ASHFORTH e HUMPHREY, 1999, } \\
\text { p.12). Falta, para as teorias sobre a motivação, a conexão emocional } \\
\text { do indivíduo com o trabalho. Conceitos como valência (atratividade } \\
\text { percebida da recompensa) e motivação intrínseca (resultado da } \\
\text { percepção de que a tarefa por si mesma é compensatória) são tratados } \\
\text { como abstrações cognitivas, percepções frias e racionalmente } \\
\text { calculadas. Tal posicionamento nega a existência de emoções como } \\
\text { surpresa, alegria, frustração e excitação dentro do trabalho. É preciso } \\
\text { desenvolver novos estudos que considerem que a motivação e o } \\
\text { envolvimento não podem ser alcançados sem uma conexão emocional } \\
\text { com o trabalho. }\end{array}$ \\
\hline Satisfação & $\begin{array}{l}\text { Para Rafaeli e Worline (2001), a satisfação passou a ser relacionada } \\
\text { ao desempenho a partir da década de } 1970 \text {, sendo posicionada como } \\
\text { a chave para a motivação no trabalho. Apesar dos grandes esforços e } \\
\text { pesquisas realizadas, os gerentes permaneceram desapontados com } \\
\text { a relação entre satisfação e uma melhor performance do trabalho. } \\
\text { Segundo as autoras apesar da satisfação ter sido inicialmente } \\
\text { definida em termos emocionais, ela foi construída como uma forma } \\
\text { racional de avaliar o trabalho em comparação a "padrões externos" } \\
\text { (expectativas de como as pessoas deveriam se comportar para se } \\
\text { satisfazer). Para Fineman (2001) A satisfação está mais próxima de } \\
\text { ser uma conexão emocional entre pessoas e organizações do que uma } \\
\text { variável numérica que interferirá na realização do trabalho. Porém, } \\
\text { ela é empregada por muitos pesquisadores como um termo grosseiro } \\
\text { para se referir as emoções. }\end{array}$ \\
\hline $\begin{array}{c}\text { Dinâmicas de } \\
\text { Grupo }\end{array}$ & $\begin{array}{l}\text { Segundo Ashforth e Humphrey (1995) as emoções, sob a perspectiva } \\
\text { de fenômeno social, estão fortemente inseridas no contexto das } \\
\text { dinâmicas de grupo, apesar dos estudos nas áreas de psicologia e } \\
\text { do comportamento organizacional sobre o tema considerarem as } \\
\text { emoções de forma implícita. A emoção está presente em termos como } \\
\text { coesividade - a atratividade de um grupo por seus membros, ou seja, } \\
\text { os laços de afetividade entre os envolvidos. Essa coesão é a chave da } \\
\text { formação, manutenção e efetividade de muitos grupos. Os autores } \\
\text { destacam que as emoções também estão fortemente relacionadas aos } \\
\text { conflitos intergrupais e intragrupais, onde o estudo das emoções têm } \\
\text { um papel muito mais importante e significativo sobre as tensões do } \\
\text { que equipamentos ou a execução de tarefas. O impacto das emoções } \\
\text { nas dinâmicas de grupo pode ser avaliado pelo contágio emocional, } \\
\text { ou seja, a forte resposta psicológica das emoções induzida ou formada } \\
\text { pelo contexto social, se referindo à tendência de copiar a forma como é } \\
\text { vivida e/ou expressa uma emoção. A expressão "espírito de equipe" } \\
\text { é fortemente baseada no fenômeno do contágio emocional. }\end{array}$ \\
\hline
\end{tabular}




\begin{tabular}{|c|c|}
\hline CONCEITO & NOVA VISÃO \\
\hline Liderança & $\begin{array}{l}\text { A liderança é a mais importante tarefa da gerência, sendo responsável } \\
\text { por elaborar e manter um sistema compartilhado de significados } \\
\text { com objetivo de criar bases para o comportamento coordenado. } \\
\text { Para Ashforth e Humphrey (1995) o líder faz uso de um sistema } \\
\text { de significados disseminados e mantidos a partir de técnicas de } \\
\text { gerenciamento - símbolos capazes de evocar emoções compatíveis } \\
\text { com os objetivos organizacionais. Em pesquisas sobre a liderança, } \\
\text { tanto teóricos como gerentes reconheceram a importância das emoções } \\
\text { nas organizações, porém sem nomeá-la. Rafaeli e Worline (2001) } \\
\text { retratam que os primeiros estudiosos se preocupavam em distanciar } \\
\text { emocionalmente o líder e os seguidores, como uma forma de impedir } \\
\text { que os sentimentos dos líderes sobre os seguidores influenciassem } \\
\text { nas suas tomadas de decisão. A segunda geração de estudiosos tem } \\
\text { focado na função emocional dos líderes, em especial ao carisma, que } \\
\text { é tido como responsável pela liderança efetiva. }\end{array}$ \\
\hline Estresse & $\begin{array}{l}\text { O estresse é resultado da exaustão e esgotamento emocional, } \\
\text { incluindo uma variedade de problemas físicos e organizacionais. } \\
\text { Para Fineman (2001), nas organizações o estresse é visto como uma } \\
\text { perigosa fraqueza pessoal e, por isso, os gerentes são treinados para } \\
\text { reconhecê-la e interferir, visto que, um empregado estressado deixa } \\
\text { de ser confiável. A organização investe em treinamento para lidar com } \\
\text { o estresse de forma superficial, como uma forma de reduzir custos } \\
\text { e transferir a responsabilidade para o próprio indivíduo que deve } \\
\text { ser capaz de lidar com o estresse, enquanto as organizações podem } \\
\text { ignorar a sua origem estrutural. Porém, o estresse não é uma emoção } \\
\text { propriamente dita e Rafaeli e Worline (2001) indicam que o estresse } \\
\text { é estudado como uma forma convencional de lidar com a emoção no } \\
\text { estudo organizacional. }\end{array}$ \\
\hline Comunicação & $\begin{array}{l}\text { É o processo de trocas de informações dentro e fora das organizações, } \\
\text { orientados por objetivos, e que tem por base, reduzir a ambigüiade } \\
\text { e a incerteza no compartilhamento, bem como, na interpretação das } \\
\text { informações transacionadas. As organizações se inserem em um } \\
\text { ambiente em constante mudança, influenciado pelas tecnologias, } \\
\text { mundo digital, uma nova ordem geopolítica, formação de redes, } \\
\text { informações sigilosas reveladas e, até mesmo, a era das notícias falsas } \\
\text { (fake news). Todos esses fatores vão impactar o desenvolvimento } \\
\text { das atividades internas da empresa. O processo de comunicação é } \\
\text { influenciado pelas emoções, de forma que as emoções experimentadas } \\
\text { durante o processo interferem na transmisãa e percepção das } \\
\text { mensagens. Assim, os gestores devem aceitar as emoções como parte } \\
\text { do processo de comunicação, antecipando cenários e compreendendo } \\
\text { quanto e como as suas emoções afetam o processo. }\end{array}$ \\
\hline
\end{tabular}

Fonte: Os autores, baseado em FINEMAN (2001); ASHFORTH E HUMPHREY (1995); RAFAELI E WORLINE (2001).

Melhorando o entendimento de tais conceitos clássicos e amplificando a compreensão para as emoções, seria possível os pesquisadores avançarem no desenvolvimento científico da Administração (FINEMAN, 2001) e criar novos olhares para as organizações, priorizando a gestão emocional, buscando reconhecer o quanto a emoção incide no crescimento e na vida das organizações. 


\subsection{GESTÃO EMOCIONAL NAS ORGANIZAÇÕES}

Baseado em Hochschild (1983) e Mesmer-Magnus et al. (2012) os estudos sobre emoção consideraram por muito tempo as emoções como forças proibidas e incontroláveis, não sendo governadas por regras sociais; enquanto o comportamento e o pensamento têm sido fortemente relacionados às concepções das regras socais. Porém, nos últimos 30 anos, os autores mostram que diferentes pesquisas têm analisado como as emoções afetam os resultados e o comportamento dos indivíduos dentro das organizações. Todos os estudos concluem: a gestão emocional é um dos elementos mais capazes de influenciar o comportamento organizacional.

A partir dessa afirmativa Hochschild $(1979 ; 1983)$ propõe uma perspectiva sobre a gestão emocional que envolve as dimensões individuais das relações e da estrutura organizacional e que, tal gestão, pode ser estudada a partir do labor emocional (emotion labor) correspondendo ao esforço do indivíduo de gerir quais emoções e com quais intensidades serão expressas externamente. O labor emocional é um processo que leva o trabalhador a subordinar suas emoções verdadeiras, de forma a expressar emoções consistentes com as expectativas do contexto de trabalho. São vários os fenômenos para futuras pesquisas nessa área, como a emoção, a inteligência emocional e o burnout.

A síndrome de burnout representa uma consequência negativa do labor emocional. Burnout é um indicativo da crescente falta de habilidade dos colaboradores de gerenciar suas próprias emoções quando em contato com outras pessoas (PEREIRA, 2002). Esta síndrome é caracterizada por um estresse profundo e crônico que impacta no exercício do trabalho. Segundo Pereira (2002) as pesquisas sobre o tema têm encontrado fortes evidências negativas entre o labor emocional e a saúde, que pode afetar a satisfação, decorrentes da Burnout. Por isso a importância de se conhecer os dois fatores à execução do labor emocional (cultura organizacional e a inteligência emocional) no processo de gerenciar as emoções (quadro 3). 


\begin{tabular}{|c|c|}
\hline Fator & Conceito \\
\hline $\begin{array}{c}\text { Cultura } \\
\text { Organizacional }\end{array}$ & $\begin{array}{l}\text { São aspectos simbólicos relacionados ao trabalho e à gestão } \\
\text { empresarial. Para Morgan (2006) uma organização não é uma } \\
\text { máquina, mas sim um organismo vivo que poderá apresentar } \\
\text { algumas subculturas devido às diferenças entre os grupos de } \\
\text { pessoas que a compõem. Jaime e Lucio (2017) definem a cultura } \\
\text { organizacional como um elo fundamental dentro das organizações, } \\
\text { capaz de ditar o ritmo, o desempenho e o futuro das atividades, } \\
\text { logo, é preciso reconhecer a cultura e as organizações - compreender } \\
\text { a importância de um olhar sociológico para os indivíduos. Sobre } \\
\text { esta questão Chanlat (2010) defende a antropologia organizacional } \\
\text { para conhecer as pessoas dentro de uma organização e o universo } \\
\text { de significados da cultura da sua gente. Todo esse vocabulário } \\
\text { cultural forma a identidade da organização (linguagem, valores, } \\
\text { normas, heróis, histórias, mitos, outros) e interfere nas decisões e } \\
\text { desempenhos organizacionais. }\end{array}$ \\
\hline $\begin{array}{l}\text { Inteligência } \\
\text { Emocional }\end{array}$ & $\begin{array}{l}\text { Inteligência emocional refere-se ao conjunto de habilidades } \\
\text { relacionados a capacidade de sentir e regular as próprias emoçôes } \\
\text { e a dos outros. Já a habilidade de gerenciar as emoções com o } \\
\text { objetivo de realizar as tarefas do trabalho é o labor emocional. Para } \\
\text { compreender como a inteligência emocional se encaixa no contexto } \\
\text { de trabalho é preciso considerá-la como um conjunto de habilidades } \\
\text { ao invés de uma característica que compõe a personalidade. "Um } \\
\text { conjunto de habilidades que hipoteticamente contribuem para a } \\
\text { expressão e uma avaliação precisa de emoções em si mesmo e nos } \\
\text { outros, a efetiva regulação de emoçôes em si e nos outros, e o uso de } \\
\text { sentimentos para motivar, planejar e atingir os objetivos de vida" } \\
\text { (SALOVEY e MAYER, 1990, p.185). }\end{array}$ \\
\hline
\end{tabular}

Fonte: Os autores a partir de SALOVEY e MAYER (1990); MORGAN (2006); CHANLAT (2010); JAIME e LUCIO (2017).

A partir do quadro3, compreende-sequeoresultadodetodososelementos que compõe a cultura organizacional resultará no clima organizacional, compreendido aqui como a atmosfera psicológica resultante das coordenações e esforços da gestão organizacional. $\mathrm{O}$ conceito de cultura organizacional reflete o grau de satisfação do indivíduo em relação ao ambiente de trabalho, sendo o mais conveniente dos métodos administrativos para gerar motivação. Envolve boa parte das variáveis citadas no quadro 2. Salovey e Mayer (1990) enfatizam que a inteligência emocional engloba habilidades como perceber os estados internos próprios e dos outros; motivações e comportamentos, de forma a extrair informações disso com o objetivo de se relacionar melhor com as pessoas. Numa perspectiva mais negativa, a inteligência emocional também inclui habilidades relacionadas à manipulação. 


\section{RESULTADOS}

\subsection{IDENTIFICANDO A EMOÇÃO NAS TEORIAS ADMINISTRATIVAS}

A importância do fator humano nas organizações é notória (MORGAN, 2006). Por mais que as máquinas e os computadores possam executar centenas e até milhares de tarefas no tempo em que uma pessoa conseguiria realizar apenas uma, são as pessoas - dotadas de raciocínio, emoção, capacidade de iniciativa, criatividade, adaptabilidade, evolução, entre outros fatores únicos da natureza humana que não podem ser copiados - o principal ativo da organização e elemento principal do sucesso empresarial. Ademais, são as pessoas os elementos encarregados de tomar decisões dentro das organizações.

Assim, nos mais variados níveis hierárquicos, são as pessoas que tomam as mais diversas decisões com base nos seus conhecimentos, experiências e ética. Dessa forma, a responsabilidade sobre o sucesso e o fracasso ou o acerto e o erro recaem sobre as mãos humanas. Devido à importância do fator humano dentro das organizações, estudar as pessoas tornou-se alvo de inúmeras análises no decorrer das décadas, sob diferentes vertentes. De acordo com Jaime e Lucio (2017) nota-se, principalmente a partir Primeira Revolução Industrial, uma forte necessidade de melhorar os processos de produção por consequência de uma crescente necessidade de extrair o máximo rendimento do trabalho humano. Para Fineman (2001) em todo esse período houve diferentes formas de como as organizações se posicionaram ao longo do tempo para aumentar o rendimento do trabalho humano.

Em um cenário onde a execução das tarefas e a gestão das empresas eram baseadas no senso comum, sem nenhum critério válido para justificar essas ações, surge o engenheiro americano Frederick Winslow Taylor (18561915), que buscou maximizar a produção a partir da racionalização do trabalho operário. Taylor (1990) estabeleceu a Teoria da Administração Científica que preconizava a melhoria através da aplicação do método científico na análise dos problemas encontrados na organização, tendo como foco o trabalho e não o trabalhador. Taylor argumenta que existe uma grande racionalidade onde o homem é visto como o "homem econômico", que visa maximizar seus rendimentos monetários e a organização é vista como uma ferramenta racional de produção.

Para Morgan (2006) uma das principais críticas à Administração Científica vem da mecanização do operário, que é visto como um apêndice do maquinário e não como um ser humano capaz de raciocinar, executar mais do que uma simples tarefa repetitiva e propor ideias para o desenvolvimento da empresa. Isso se deve ao fato de ser baseada na fria lógica da engenharia e na necessidade de replicação em outros ambientes, deixando de lado os sentimentos e as emoções dos envolvidos. Dessa forma a Administração 
Científica busca apenas eliminar os efeitos negativos dos sentimentos e dos fatores sociais.

Com relação à Teoria Administrativa temos que esta surgiu paralelamente à Escola da Administração Científica, contudo, seu foco era a busca da eficiência através da estrutura da empresa. Esse movimento foi iniciado na França por Henri Fayol (1841-1925) que se preocupou com a administração na totalidade da organização. Seu trabalho se iniciou de cima, dos dirigentes, até alcançar os operários (top down). Ele estudou as tarefas do dirigente de forma a eliminar seus esforços inúteis e propôs que o processo administrativo poderia ser dividido em áreas de responsabilidade ou funções interdependentes. Dentro dessa visão, Fayol (1990) apresenta que cada indivíduo deveria ter uma função bem definida, cabendo à pessoa se adaptar a função e não a função à pessoa. As ações são limitadas, a estrutura foi criada de forma a permitir apenas às ações planejadas, logo, a emoção também não era considerada. Fayol foi muito criticado por se restringir ao estudo da estrutura da empresa. Seu trabalho estava limitado a "organização e métodos", a eficiência seria alcançada após se determinar os órgãos, suas funções e como deveriam se relacionar.

Fineman (2001) argumenta que os trabalhos de Taylor e Fayol são marcados pela exclusão, remoção ou controle das emoções e sentimentos dentro da organização. A visão dos dois estudiosos de que o homem na organização era uma extensão das máquinas reflete o não entendimento da forte hostilidade existente por parte dos operários, quando propostos então os novos modelos de produção. Para o autor, a resposta para as emoções que ameaçassem o fluxo de trabalho era a implantação de formas de controle emocional cada vez mais rígido. $\mathrm{O}$ fracasso de Taylor em sua primeira tentativa de implantar um novo sistema para aumentar a produtividade pode ser atribuído à segregação da emoção dentro das organizações. Essa visão de que as emoções devem ser controladas e evitadas dentro das organizações também é evidente no trabalho de Max Weber, popularizado por Parsons (2010), visto que, o seu conceito de burocracia ideal é um sistema livre de todos os elementos puramente pessoais, irracionais e emocionais, como ódio e amor. Todo esse desprezo sobre a emoção é resultado das crenças da cultura ocidental, em especial masculinas, de que as emoções são irracionais e por isso devem ser controladas e evitadas nas organizações.

Subsequentemente temos a Escola das Relações Humanas (ERH), onde Elton Mayo (1880-1949) é considerado como referência deste movimento. Esta escola é a primeira a enfatizar os estudos do comportamento humano destacando seu foco na organização informal, que se refere ao conjunto de relações sociais não previstas na estrutura da organização, ou, a impossibilidade de se reduzir o comportamento a reações mecânicas e automáticas. Para Motta e Vasconcelos (2006) essa escola foi marcada pela predominância de psicólogos, que, como tal, entendiam as organizações como grupos de pessoas e atribuíam os problemas organizacionais como reflexos dos problemas individuais. Apesar disso, 
fracassaram em explicar a relação entre satisfação e produtividade, não sendo capazes de ilustrar porque, em alguns casos, os funcionários mais insatisfeitos eram mais produtivos do que os mais satisfeitos. Motta e Vasconcelos (2006) destacam que a ERH focou nos aspectos emocionais do ambiente de trabalho e defendem a ideia que as pessoas que possuem sentimentos de pertencer ao grupo produzem mais; as condições sociais no ambiente de trabalho afetam significativamente a produtividade; a importância da colaboração em uma organização; e que os grupos informais são fundamentais para a comunicação.

Destacamos, ainda, os primeiros estudos de Mary Parker Follett e sua visão sobre a importância do desenvolvimento individual, para o bem-estar, a sociedade e a gestão dos negócios. Fineman (2001) defende que nesse período a emoção foi estudada de forma camuflada, havendo um grande número de estudos sobre o comportamento ligado a emoções negativas e, em menor escala, sobre a felicidade e prazer no trabalho. Apesar disso, a ERH merece destaque pela preocupação com o indivíduo para se alcançar a eficiência, opondo-se a ênfase das escolas anteriores.

A Escola Comportamentalista nasce como um desdobramento da Escola de Relações Humanas e traz uma maior valorização do comportamento humano em contraste as posturas normativas e descritivas das escolas anteriores, criticando fortemente a visão mecanicista da Escola Clássica. Essa escola é caracterizada pela forte presença da psicologia, onde os seus estudiosos se dedicaram a entender o ajustamento pessoal do indivíduo na organização e quais efeitos são causados pelas relações intergrupais e pelos estilos de liderança. Existe um forte enfoque no estudo dos indivíduos e dos grupos nas organizações, caracterizando o estudo do comportamento organizacional. Destacam-se as contribuições do alemão Kurt Lewin (1890-1947), que foi capaz, dentre tantas pesquisas, de guiar experimentos de grupo para medir a atmosfera de liderança. O núcleo central dos estudos de Lewin (1978) são as dinâmicas de grupo. Nesta escola também merece evidência as contribuições de Abraham Maslow (1908-1970), que criou a Teoria da Hierarquia das Necessidades com o objetivo de explicar a motivação humana e de Rensis Likert (1903-1981) e seus estudos sobre liderança - impacto no desempenho e satisfação com o trabalho.

Dessa forma, compreende-se que os estudiosos da Escola Comportamentalista analisaram as emoções e os sentimentos humanos de forma superficial. Apesar disso, foram capazes de contribuir muito para o entendimento das motivações humanas; a busca pela satisfação das necessidades dos indivíduos; o impacto dos estilos de liderança. Fineman (2001) argumenta que esse período também foi marcado pelo enfoque na negatividade das emoções, tendo forte influência da psicanalise organizacional que introduziu os conceitos de "desejos e ansiedades inconscientes que estão expressos nos processos organizacionais de liderança, estrutura e funcionamento dos grupos" (FINEMAN, 2001, p.158). Para o autor, os movimentos que ocorreram após a década de 1970 têm como enfoque a criação e propagação das emoções 
positivas. Surge a ideia de modificar o ambiente físico, remodelar a cultura organizacional e fortalecer a comunicação, de forma a fomentar a alegria e o divertimento no trabalho. Sentir-se-bem seria o elemento chave para o sucesso gerencial.

\subsection{A EMOÇÃO NAS PUBLICAÇÕES NACIONAIS}

Evidenciado a importância da gestão emocional, como ela foi percebida pelas teorias administrativas e como ela pode ser estudada na Administração, esta etapa do trabalho pretende apresentar como a emoção está sendo empregada nos estudos e pesquisas da Administração no Brasil, a partir de quatro categorias analíticas: emoção nas práticas organizacionais; emoção como experiência (marketing); gestão da emoção; e emoção no processo de decisão (racionalidade), todas apresentadas no quadro 4 (mais abaixo). As categorias foram criadas após a leitura dos artigos encontrados, onde observou-se que alguns aglutinavam-se entre si devido a visão que apresentava sobre a emoção. Ademais, informamos que este levantamento ocorreu entre os meses de março e julho de 2019.

A primeira categoria analisada engloba quatro artigos que interpretam a "emoção como 'experiência' (marketing)", algo emocionante - o que difere totalmente do apresentado aqui neste estudo. É o caso dos artigos que abordam a temática da emoção em restaurantes gastronômicos, no Cirque Du Soleil; no conteúdo das propagandas; e nos meios de hospedagem. Aqui a emoção é empregada em sentido metafórico, como sinônimo de experiência e os artigos defendem que esta é importante por proporcionar uma vantagem competitiva às empresas. Ou seja, nenhum deles defende a gestão da emoção conforme narrado neste estudo.

Quadro 4 - Artigos encontrados na base SPELL

\begin{tabular}{|c|c|c|c|c|c|}
\hline ARTIGO & AUTORES & PERIÓDICO & ANO & CITAÇÃO & $\begin{array}{l}\text { CATEGORIA } \\
\text { ANALÍTICA }\end{array}$ \\
\hline $\begin{array}{l}\text { Prática docente no ensino } \\
\text { de Administração: } \\
\text { analisando a mediação da } \\
\text { emoção }\end{array}$ & \begin{tabular}{|c|} 
Liliane Canopf \\
Jucelia Appio \\
Yara Lúcia M. \\
Bulgacov \\
Denise de Camargo
\end{tabular} & $\begin{array}{l}\text { Organizações } \\
\text { \& Sociedade }\end{array}$ & 2018 & 0 & \multirow{3}{*}{$\begin{array}{c}\text { Emoção } \\
\text { nas práticas } \\
\text { organizacionais }\end{array}$} \\
\hline $\begin{array}{c}\text { Dimensão ideológica } \\
\text { da emoção na gestão de } \\
\text { vendedoras de cosméticos } \\
\text { em uma empresa } \\
\text { multinacional } \\
\end{array}$ & \begin{tabular}{|c|} 
Rossana Cristine \\
F. Jost \\
Yara Lúcia M. \\
Bulgacov \\
Denise de Camargo \\
\end{tabular} & $\begin{array}{l}\text { Cadernos } \\
\text { EBAPE.BR }\end{array}$ & 2018 & 0 & \\
\hline $\begin{array}{l}\text { A positividade da emoção } \\
\text { na prática da pesquisa } \\
\text { social em organizações }\end{array}$ & $\begin{array}{l}\text { Yara Lúcia M. } \\
\text { Bulgacov } \\
\text { Fábio Vizeu }\end{array}$ & $\begin{array}{c}\text { Cadernos } \\
\text { EBAPE.BR }\end{array}$ & 2011 & 4 & \\
\hline
\end{tabular}




\begin{tabular}{|c|c|c|c|c|c|}
\hline ARTIGO & AUTORES & PERIÓDICO & ANO & CITAÇÃO & $\begin{array}{l}\text { CATEGORIA } \\
\text { ANALÍTICA }\end{array}$ \\
\hline $\begin{array}{c}\text { Emoção como signo dos } \\
\text { espaços em meios de } \\
\text { hospedagem }\end{array}$ & $\begin{array}{c}\text { Luciano T. Tricárico } \\
\text { Mônica S. de } \\
\text { Vargas }\end{array}$ & $\begin{array}{l}\text { Caderno } \\
\text { Virtual de } \\
\text { Turismo } \\
\end{array}$ & 2017 & 0 & \multirow{4}{*}{$\begin{array}{l}\text { Emoção como } \\
\text { "experiência" } \\
\text { (marketing) }\end{array}$} \\
\hline $\begin{array}{c}\text { Andando na corda } \\
\text { bamba? análise da } \\
\text { fragilidade da emoção } \\
\text { como vantagem } \\
\text { competitiva na criação de } \\
\text { valor do Cirque Du Soleil }\end{array}$ & $\begin{array}{c}\text { Felipe C. Almeida } \\
\text { Alyne Oliveira Vale } \\
\text { Sérgio H. A. C. } \\
\text { Forte }\end{array}$ & $\begin{array}{l}\text { Revista Ibero- } \\
\text { Americana de } \\
\text { Estratégia }\end{array}$ & 2010 & 0 & \\
\hline $\begin{array}{l}\text { Informação e emoção na } \\
\text { propaganda: uma análise } \\
\text { de conteúdo na internet } \\
\text { no Brasil }\end{array}$ & $\begin{array}{l}\text { Melby K. Z. } \\
\text { Huertas } \\
\text { Antonio C. Segura }\end{array}$ & $\begin{array}{l}\text { Revista } \\
\text { Brasileira de } \\
\text { Marketing }\end{array}$ & 2011 & 2 & \\
\hline $\begin{array}{l}\text { Emoção, ambiente e } \\
\text { sabores: a influência } \\
\text { do ambiente de } \\
\text { serviços na satisfação } \\
\text { de consumidores } \\
\text { de restaurantes } \\
\text { gastronômicos }\end{array}$ & $\begin{array}{l}\text { Viviane Santos } \\
\text { Salazar } \\
\text { Salomão A. de } \\
\text { Farias } \\
\text { Rafael Lucian }\end{array}$ & $\begin{array}{l}\text { Revista } \\
\text { Observatório } \\
\text { de Inovação } \\
\text { do Turismo }\end{array}$ & 2008 & 2 & \\
\hline $\begin{array}{l}\text { Secretária Executiva: } \\
\text { estresse e emoção no } \\
\text { trabalho }\end{array}$ & $\begin{array}{l}\text { Cibele Cristina } \\
\text { Ortega } \\
\text { Luis Fernando } \\
\text { Araujo }\end{array}$ & $\begin{array}{l}\text { Revista de } \\
\text { Gestão e } \\
\text { Secretariado }\end{array}$ & 2011 & 0 & \multirow{3}{*}{$\begin{array}{l}\text { Gestão da } \\
\text { emoção }\end{array}$} \\
\hline $\begin{array}{c}\text { Ampliando o } \\
\text { entendimento sobre a } \\
\text { emoção existente nas } \\
\text { interações de serviços }\end{array}$ & $\begin{array}{l}\text { Gabriel Sperandio } \\
\text { Milan }\end{array}$ & $\begin{array}{c}\text { Revista } \\
\text { Brasileira de } \\
\text { Gestão de } \\
\text { Negócios } \\
\end{array}$ & 2007 & 6 & \\
\hline $\begin{array}{c}\text { A emoção e o seu } \\
\text { impacto na integração } \\
\text { humana em processos } \\
\text { de fusão / aquisição nas } \\
\text { organizaçôes }\end{array}$ & $\begin{array}{l}\text { Cinira Marcondes } \\
\text { Juliana Vantine }\end{array}$ & $\begin{array}{c}\text { Revista } \\
\text { Administração } \\
\text { em Diálogo }\end{array}$ & 2010 & 0 & \\
\hline $\begin{array}{l}\text { O que determina a } \\
\text { tomada de decisão } \\
\text { financeira: razão ou } \\
\text { emoção? }\end{array}$ & $\begin{array}{l}\text { José Odálio dos } \\
\text { Santos } \\
\text { Carlos Augusto } \\
\text { Barros } \\
\end{array}$ & $\begin{array}{l}\text { Revista } \\
\text { Brasileira de } \\
\text { Gestão de } \\
\text { Negócios } \\
\end{array}$ & 2011 & 2 & \multirow{4}{*}{$\begin{array}{c}\text { Emoção no } \\
\text { processo } \\
\text { de decisão } \\
\text { (racionalidade) }\end{array}$} \\
\hline $\begin{array}{l}\text { A interferência da } \\
\text { emoção na tomada de } \\
\text { decisão de risco: um } \\
\text { estudo experimental } \\
\text { com profissionais da } \\
\text { controladoria } \\
\end{array}$ & $\begin{array}{c}\text { Tamar K. } \\
\text { Alvarenga } \\
\text { Ricardo L. Cardoso } \\
\text { Jandira S. Ferreira } \\
\text { Andson B. de } \\
\text { Aguiar } \\
\end{array}$ & $\begin{array}{l}\text { Revista } \\
\text { Universo } \\
\text { Contábil }\end{array}$ & 2014 & 0 & \\
\hline $\begin{array}{l}\text { Mercado de Capitais: } \\
\text { racionalidade versus } \\
\text { emoção }\end{array}$ & $\begin{array}{l}\text { José Odálio dos } \\
\text { Santos } \\
\text { José Augusto R. } \\
\text { Santos }\end{array}$ & $\begin{array}{c}\text { Revista } \\
\text { Contabilidade } \\
\text { \& Finanças - } \\
\text { USP }\end{array}$ & 2005 & 3 & \\
\hline $\begin{array}{l}\text { Retórica Organizacional: } \\
\text { lógica, emoção e ética no } \\
\text { processo de gestão }\end{array}$ & $\begin{array}{l}\text { Alvair Silveira } \\
\text { Torres Junior }\end{array}$ & $\begin{array}{c}\text { Revista de } \\
\text { Administração } \\
\text { de Empresas }\end{array}$ & 2002 & 0 & \\
\hline
\end{tabular}

Fonte: Dados da pesquisa.

Outros quatro artigos se enquadram na categoria "emoção no processo de decisão (racionalidade)". Aqui os artigos abordam a emoção enquanto sinônimo de emocionante e a ênfase era avaliar a influência da emoção no processo de tomada de decisão, na racionalidade. Isso não é novo, onde podemos destacar os estudos de Herbert Simon (O Comportamento Administrativo, 1947). Apesar de uma proximidade com o tema aqui tratado, os quatro artigos delineiam a emoção como algo negativo, que pode atrapalhar a racionalidade 
necessária para a tomada de decisão. Logo o defendido pelos autores vai de encontro com a visão das primeiras teorias administrativas que tratavam a emoção como algo negativo e que tinha que ser controlada e extinguida de dentro das organizações.

A próxima categoria, "emoção nas práticas organizacionais", contém três artigos que têm em comum uma autora: a professora Yara Bulgacov. Em geral os três artigos buscam avaliar os processos de constituição, reprodução e criação das práticas sociais ligadas ao humano no cotidiano organizacional. Todos têm grande influência de Vygotsky em suas obras sobre imaginação, psicologia e formação social. Os artigos buscam analisar a mediação da emoção nas práticas organizacionais (dois na área de ensino e um na área de vendas). Para evidenciar a emoção na prática. Os artigos analisam itens como a cultura, a construção social, as práticas dos atores e o comportamento organizacional. No fim, apresentam uma relação entre a razão e a emoção no processo de conhecer. Nos três casos, há grande influência da psicanálise com ênfase no sujeito. $\mathrm{O}$ foco principal é evidenciar as práticas - a emoção aparece em segundo plano, como elemento influenciador das práticas. No geral, são excelentes artigos empíricos e que servem de boa inspiração para futuras pesquisas com olhar diferenciado sob novos fenômenos.

A última categoria é a "gestão da emoção" e, de todas as categorias é a que mais se aproxima do debate teórico empreendido neste artigo. Os três artigos destacam a importância das organizações gerenciarem a emoção, na perspectiva de Hochschild (1983) e Fineman (2001). O primeiro artigo, e mais citado de todos, foi elaborado em 2007 por Gabriel Milan intitulado "Ampliando o entendimento sobre a emoção existente nas interações de serviços". O autor defende que sejam organizados novos estudos sobre a emoção e traz uma breve discussão teórica sobre o que é emoção e a importância de as organizações gerenciá-las. Neste artigo, o autor da ênfase ao processo de emoção entre a empresa e os clientes, o que também é importante. Embora o artigo de Milan não demostre os relacionamentos internos e a gestão emocional dos colaboradores, este artigo traz o olhar da emoção para outro fenômeno, o que não desabona a qualidade, pelo contrário, convoca que novas pesquisas sejam realizadas.

O segundo artigo desta quarta categoria propõe uma discussão reflexiva por meio de uma abordagem teórica a respeito da emoção no contexto dos serviços. Cinira Marcondes e Juliana Vantine (2008) analisam a emoção dos trabalhadores quando ocorre a fusão/aquisição de novas organizações. $\mathrm{O}$ tema é bem atrativo e de suma importância para a ciência da Administração. Pesquisaram três grandes empresas (farmacêutica, telecomunicações e financeira) onde, por meio de uma pesquisa quantitativa, queriam descobrir dimensões dominantes da experiência emocional no processo de fusão. Os resultados mostram que é necessário um intenso cuidado com as emoções presentes em processos de fusão, onde a construção harmoniosa de um novo caminho beneficiará a todos, à medida que ficarem evidentes as possibilidades 
de sinergia para potencializar a proposta de valor aos indivíduos e a sociedade. Daí a importância da inteligência emocional e da cultura organizacional.

Por fim, o terceiro artigo desta quarta categoria, de autoria de Cibele Ortega e Luis Araújo (2011), busca analisar o estresse e a emoção no trabalho das secretárias executivas. Os autores realizaram um bom levantamento teórico sobre emoção e estresse e focaram nas principais doenças laborais, como a depressão, síndrome do pânico e a síndrome de Burnout. O objetivo da pesquisa era saber se as secretarias trabalham sob pressão. A pesquisa foi aplicada junto a 30 secretarias da cidade de São Paulo e os resultados mostram um alto índice de estresse decorrente de suas práticas laborais e isso impacta no rendimento, na produtividade e no dia a dia das organizações. Os autores concluíram que é preciso gerenciar as emoções e criar um ambiente mais amistoso para as secretarias.

A partir da leitura dos catorze artigos indexados na área da Administração, observa-se que a produção ainda é baixa. No interim de 16 anos (2002, data do primeiro artigo - 2018, o último) a produção se concentra em quatro grandes grupos, dos quais, apenas um grupo (gestão da emoção) dá ênfase à importância de olhar para o indivíduo como fonte de ideias, um sujeito singular, com personalidade e sentimentos. $\mathrm{O}$ baixo resultado nacional vai de encontro ao apresentado por Fineman (2001- há 19 anos) e Domagalski (1999- há 21 anos), quando os autores argumentam que em 1990, nos Estados Unidos, a emoção era objeto de estudo, sobretudo, nos campos da psicologia e da sociologia das emoções. Apesar das contribuições de psicólogos e sociólogos, temos que o objeto de estudo da Administração é a organização, logo a necessidade de administradores estudarem a emoção nas organizações.

Igualmente, no Brasil vale à pena destacar a contribuição dos estudos de Mirele Cardoso Bonfim e Sônia Maria Guedes Gondim que são influenciadas por Hochschild, Fineman, Ashforth e Humphrey dentre outros nomes e buscam analisar emoção e o impacto do afeto no ambiente organizacional. Uma de suas principais obras é "trabalho emocional - demandas afetivas no exercício profissional". Igualmente, temos as contribuições da Revista Brasileira de Sociologia da Emoção (RBSE) que desde 2002 vem apresentando inúmeras publicações sobre a emoção. Logo, o tema é vertiginoso e seu crescimento precisa ser acelerado pelos pesquisadores brasileiros.

\section{CONSIDERAÇÕES FINAIS}

Buscamos neste estudo apresentar uma proposta teórico-analítica que permita uma maior compreensão sobre a importância de gerenciar a emoção e, também, que contribua com a disseminação de pesquisas em relação à emoção dentro das organizações, sobretudo na Administração. Optamos por identificar no clássico estudo das teorias administrativas qual era a visão da emoção no processo de organizar, para então, apresentar como se deu a sua popularização 
e a disseminação de grandes obras/estudos na década de 1970-80, chegando a sua atual aplicação no Brasil, como é o caso das pesquisas encontradas na SPELL que percebem diferentes vertentes da emoção.

Através da revisão teórica constatamos que as primeiras teorias administrativas visavam controlar as emoções e os sentimentos. Somente a partir da teoria comportamentalista é que há um grande desdobramento na Administração e uma maior ênfase à importância da gestão emocional. Acreditava-se que através da racionalidade seria possível controlar as emoções. Ideia essa descartada por Fineman.

Durante o levantamento de pesquisas atuais realizadas na Administração ficou claro que, na maioria dos casos, esta vem sendo empregada em seu sentido metafórico, como sinônimo de experiência, algo comovedor. Ainda são poucos os artigos que examinam a importância da emoção do indivíduo para o desenvolvimento das organizações. A partir da teoria apresentada e das pesquisas encontradas conclui-se que existe uma crescente necessidade de se avaliar o impacto do bem-estar emocional no desempenho profissional e na busca pela eficiência da organização. A emoção (re)surge como uma nova área de interesse e seu gerenciamento poderá possibilitar às organizações um diferencial competitivo.

Grande parte dos estudos sobre emoção tem como base os trabalhos de Hochschild, Fineman, Ashforth e Humphrey, não pelo pioneirismo, mas por eles considerarem a emoção como um fenômeno natural do ser humano. As transformações paradigmáticas apresentadas por estes autores geraram um novo olhar e muito impacto na abordagem comportamental das organizações, em pesquisas desenvolvidas nos EUA e em países de língua francófona, com destaque para a influência de Chanlat. Esses pesquisadores evidenciaram que negar a existência ou controlar rigidamente as emoções não é a melhor maneira de gerir as pessoas. Todos destacam a necessidade e a importância de se investir em novos estudos sobre o tema.

A pesquisa nacional, obtida a partir da plataforma SPELL, comprova que os administradores ainda precisam aprofundar os estudos e considerar a emoção como um novo capital dentro das organizações. É evidente a necessidade de se compreender como os estudos sobre a emoção nas organizações ocorreram até aqui e como os atuais pesquisadores vem contribuindo para o desenvolvimento desses conhecimentos - o avanço na compreensão do fenômeno humano. No entanto, observamos que a influência da TGA e de estudos meramente estrutural e normativo ainda é um imperativo forte entre os pesquisadores, o que limita o crescimento de uma abordagem científica da Administração capaz de compreender o indivíduo dentro das organizações.

Dessa forma, propomos que novas pesquisas sejam realizadas podendo ser considerada a emoção dos indivíduos a partir de questões como os símbolos, a inveja, a influência digital, sexualidade e trabalho, homofobia, fake news, expatriação, migrações e racismo e outras dimensões atuais que permitam 
compreender a complexidade humana e o avanço da ciência da Administração. Nessa vertente, sugerimos que essas temáticas sejam articuladas aos dois fatores à execução do labor emocional (cultura organizacional e inteligência emocional) e a nova visão da emoção dentro do ambiente organizacional, como na motivação, liderança, dinâmicas de grupo e outros apresentados no quadro 2. Ademais, acreditamos que é preciso elaborar um estudo mais orgânico dos indivíduos nas organizações. Assim, incitamos a realização de pesquisas a partir de uma observação participante, postura etnográfica, história de vida, grupo focal, dentre outras técnicas que permitirão um maior acompanhamento da experiência do indivíduo.

Não podemos mais ocultar a importância de estudar a emoção dos indivíduos dentro das organizações. O seu emprego nas pesquisas do campo da Administração abre um amplo leque de possibilidades, tanto em termos das descobertas que podem enriquecer a teoria das organizações, como no avanço do conhecimento em diversas áreas específicas de interesse dos pesquisadores de campo, tendo em vista, a natureza interdisciplinar do tema e as particularidades de cada área do conhecimento. A temática é atual, reflexiva e prática e esta tem que ser objeto de interesse de pesquisadores, executivos e gestores.

\section{REFERÊNCIAS}

ASHKANASY, N.M. Studies of cognition and emotion in organizations: attribution, affective events, emotional intelligence and perception of emotion. Australian Journal of Management. v.27, n.1, p.11-20, 2002.

ASHFORTH, B. E.; HUMPHREY, R. H. Emotion in the workplace: a reappraisal. Human Relations. v.48, n.2, p.97-125, 1995.

BONFIM, M.C.; GONDIM, S.M.G. Trabalho emocional: demandas afetivas no exercício profissional. Salvador: EDUFBA, 2010.

BROOK, P. In critical defense of 'emotional labor' refuting Bolton's critique of Hochschild's concept. Work, employment and society. v.23, n.3, p.531-548, 2009.

CHANLAT, J.-F. L'Individu dans L' Organísatian - les dimensions oubliéc. Québec, Canadá : Les Presses de l’Université Lavai, Editions ESKA, 1990.

CHANLAT, J.-F. Entrevista com Jean-François Chanlat. In. Freitas, M. E. GVexecutivo. v.7, n.1, p.62-69, 2008.

CHANLAT, J.-F. Gestão Empresarial: uma perspectiva antropológica. São Paulo: Cengage Learning, 2010. 
CRUZ, B. P. A.; ROSS, S. D. Caminhos Sinuosos: os deslizes nos estudos em Administração Pública e de Empresas. Administração: ensino e pesquisa. v.19, n.2, p.200-242, 2018.

DOMAGALSKI, T. A. Emotion in Organizations: Main Currents. Human Relations. v.52, n.6, p.833-852, 1999.

SANTO, A. L. O Uso de Fotografias e Vídeos em Pesquisa Qualitativa: em Busca de um Novo Olhar sobre os Territórios Fronteiriços. Revista Adm.Made. v.22, n.2, p.1334, 2018.

FAYOL, H. Administração Industrial e Geral: Previsão, Organização, Comando, Coordenação e Controle. São Paulo: Atlas, 1990.

FINEMAN, S. A emoção e o processo de organizar. In: CLEGG, S. R.; HARDY, C.; NORD, W. R. (Org). Handbook de estudos organizacionais: modelos de análise e novas questões em estudos organizacionais. São Paulo: Atlas, 2001

HOCHSCHILD, A.R. Emotion work, feeling rules, and social structure. American Journal of Sociology. v.85, n.3, p.551-575, 1979.

HOCHSCHILD, A.R. The Managed Heart: Commercialization of Human Feeling, With a New Afterword. Universidad of California Press, 1983.

HOCHSCHILD, A.R. Feeling around the world. Contexts. 7(2), 65-80, 2008.

JAIME, P.; LUCIO, F. Sociologia das Organizações: conceitos, relatos e casos. São Paulo: Cengage Learning, 2017.

KUHN, T. S. A Estrutura das Revoluções Científicas. São Paulo: Perspectiva, 2017.

LEWIN, K. Problemas de Dinâmica de Grupo. São Paulo: Cultrix, 1978.

LIKERT, R. Novos Padrões de Administração. São Paulo: Biblioteca Pioneira, 1979.

MESMER-MAGNUS, R. et.al. A Moving emotional labor beyond surface and deep acting. Organizational Psychology Review. v.2, n.1, p.6-53, 2012.

MORGAN, G. Imagens da Organização. São Paulo: Atlas, 2006.

MOTTA, F.C.P.; VASCONCELOS, I.F.G. Teoria Geral da Administração. São Paulo: Cengage Learning, 2006.

PARSONS, T. Estrutura da ação social Vol. II - Weber: Um estudo de teoria social com especial referência a um grupo de autores europeus recentes. São Paulo: Editora Vozes, 2010.

PEREIRA, A.M. Burnout: quando o trabalho ameaça o bem-estar do trabalhador. Casa do psicólogo, 2002. 
RAFAELI, A.; WORLINE, M. Individual emotion in work organizations. Social Science Information. v.40, n.1, p.95-123, 2001.

SALOVEY, P.; MAYER, D. Emotional intelligence. Imagination, cognition and personality. v.9, n.3, p.185-211, 1990.

TAYLOR, F. W. Princípios de Administração Científica. São Paulo: Atlas, 1990. 